\title{
Inquietud agustiniana: Tomás de Argentina ${ }^{(1)}$
}

Es éste uno de los problemas más típicos de la llamada "Escuela Agustiniana". Incluso, para muchos constituiría su tema fundamental. Nosotros lo examinaremos aquí en uno de los representantes más fieles y destacados ${ }^{2}$, teniendo en cuenta,

1 Tema muy socorrido entre teólogos y filósofos, las revistas le han dado acogida en sus páginas. Se ha escrito muchísimo sobre este problema. He aquí algunas muestras: P. BASTABLE, Desire for God, London-Dublín 1947; G. DE BoGLIE, De fine ultimo Humanae Vitae, París 1948; V. CaTHREIN, "De naturali hominis beatitudine": Gregorianum 11 (1930) 398-409; P. M. CuERvo, "El deseo natural de ver a Dios y los fundamentos de la apologética inmanentista": Ciencia Tomista 38 (1928) 332-348; 39 (1929) 5-36 y 45 (1932) 289-317; F. CAYRE, Dieu present dans la vie de l'esprit, París 1951; L. Cillenuelo, "La memoria sui": Giornale di Metafisica 9 (1954) 478-492; A. GARDEIL, "Le désir naturel de voir Dieu": Revue Thomiste (1926) 381-410; H. DE LuBAC, Surnaturel, París 1946; ID., Le mystère du surnaturel, París 1965; J. MoRÁN, "Hacia una comprensión de la "memoria Dei" según San Agustín": Augustiniana 10 (1960) 83-110; F. Piemontese, "Il "cuore" di Pascal e il Razionalismo in Filosofia": Giornale di Metafisica 21 (1966) 270-280; P. Rostenne, "Pour une metaphysique de l'Amour": Giornale di Metafisica 21 (1966) 239-264. La bibliografía sobre el tema que traemos entre manos es amplísima. Mauricio Blondel toca en casi to.

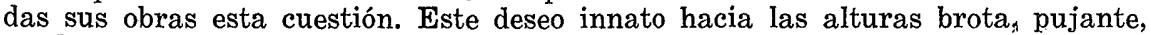
ya desde su juventud, en los escritos de Teilhard de Chardin. Puede consultarse también las obras siguientes: H. DUMERY, Raison et religion dans la philosophie de l'action, París 1963; ID., Philosophie de la religion y Critique et Religion, París 1957; H. Boulllard, Logique de la foi. Esquisses. Dialogues avec la pensée protestante. Approches philosophiques, París 1964. Para una información más completa, puede verse la obra del P. J. AlFARo, Lo natural y lo sobrenatural. Estudio histórico desde Santo Tomás hasta Cayetano (1274-1534), Madrid 1952.

2 Cfr. H. HURTER, Nomenclator Literarius, IV, Oeniponte, 1899, 507-508, de quien escribe: "A doctrinae profunditate magnopere commendatus... Ob concinnam brevitatem magni factum et saepe adhibitum fuit in veteri schola aegidiana"; E. DE LA PRESENTACIÓN, De immaculata Virginis Conceptione ab omni peccato immuni libri quattuor, Conimbricae 1617. En el lib. 3, q. 3, a. 4, p. 325, afirma de Tomás de Argentina que es "Aegidii accerrimus defensor"; J. SHANNON, Good Works and Predestination according to Thomas of Strassburg, O .S. A., Baltimore 1940. En la Introducción, p. 1, escribe: "He was... a devoted follower and lucid expositor of Giles of Roma, who is the founder of the Augustinian School-a School which, on that account frequently termed school aegidiana. Both on account of his own contribution to the theological thougth of his time and on account of his pronounced influence on the Augustinian School, Thomas of Strassburg commands the serious attention"; M. Grabmann, Historia de la Teología Católica, trad. D. Gutiérrez, Madrid 1946. En la página 131 puede leerse: "Junto al Beato Santiago de Viterbo hay que colocar por su importancia y por el influjo que ejerció dentro de la Escuela, al que después fue superior general de toda la Orden, Tomás de Argentina $(\dagger$ 1357)"; D. TRAPP, "Augustinian Theology of the 14th Century": Augusti- 
por otra parte, que él mismo confiesa su lealtad al sistema peripatético entonces vigente ${ }^{3}$. Así comprenderemos mejor y resaltará más la influencia evidente del problema en los maestros de la Escuela en cuestión.

Como es obvio, Tomás de Estrasburgo relaciona el deseo innato, natural al mismo tiempo que necesario, inmediatamente con la voluntad, coherente con su postura mental de hacer consistir la felicidad formal del hombre en una volición, es decir, en la fruición perfecta y en la complacencia completa que son esencialmente actos, ante todo, del apetito intelectivo o voluntad ${ }^{4}$. También en esto procede con auténtica lógica, ya que es un defensor ferviente de la primacía psicológica, ética y metafísica de la voluntad sobre el entendimiento. El hecho mismo de que nuestro autor haya dado a este problema una extensión y unos horizontes amplísimos demuestra el gran interés que concede a su estudio ${ }^{5}$.

\section{ESENCIA DE LA FELICIDAD.}

Es preciso concretizar al máximo el pensamiento de Tomás, aún a costa de resultar demasiado sintéticos.

niana 6 (1956) 146-272. En la p. 177 formula su juicio crítico sobre el Agustino: "Once Thomas of Strassburg had been printed he remained popular through the following centuries. Completeness in regard to all of Lombard's Problems, clarity and conciseness of exposition, rich documentation in historical theology. all these advantages gave Thomas a place of honor on the shelves and desks of theologians belonging to the post-reformation period and even to the movement of scholastic revival". A su vez el P. David Gutiérrez anota: "Demuestran bien la difusión del excelente curso teológico de Tomás de Estrasburgo los numerosos códices que aún lo conservan y las ediciones que obtuvo desde el siglo XV hasta el XVII. Martín Grabmann tenía siempre sobre su mesa de estudio un ejemplar de esta obra, que recomendaba a sus discípulos de la Universidad de Munich como libro representativo de la buena escolástica del siglo XIV"; D. GUTIÉRREZ, "Al margen de libros y artículos acerca de Lutero": La Ciudad de Dios 169 (1956) 611. Cfr. B. LINDNER, Die Erkenntnislehre des Thomas von Strassburg, Münster 1930.

Acerca de las obras escritas por nuestro autor escribe HuRTen en el lugar citado: "Reliquit lecturam in 4. li. Sententiarum", Argentorati 1490 (m. 28); accedunt decisiones et quaestiones, quae a diversis theologis pertractantur, cum autoris vita, Venetiis 1564 (m. 36); 1588; Genuae 1585; Genevae 1635 in f. de quo opere scribit. Franc. Macedo in conceptu euchologico: "Aureus hic doctor argenteam suam doctrinam Augustini sententiis inauravit...".

Quisiéramos hacer constar que las citas de este modesto trabajo se realizarán conforme a la edición de 1585.

3. "Sed quia quasi omnes Peripatetici, quos ego seguor in Philosophia, ubi eorum dicta fidei non repugnant" (I, d. 35 , q. 1, a. 4, fol. 106v, col. 2).

4 Se enfrenta con este problema en diferentes lugares. Cfr. I, d. 1, q. 1, a. 1; I, d. 1. q. 3, a. 2; IV, d. 49, q. 3, a. 2; I, d. 1, q. 1, a. 2 y 3; I, Prol., q. 3, a. 1; IV, d. 49, q. 2, a. 3... Passim.

5 Claro partidario de la primacía de la voluntad va diluyendo su pensamiento de modo directo o indirecto en diversas doctrinas de su Comentario. Cfr. I, Prol., q. 4, a. 1; II, d. 16, q. 1, a. 1; II, d. 16, q. 1, a. 3 y 4; I, Prol., q. 4, a. 2 ; IV, d. 14 , q. 1 , a. 2 ; IV, d. 2 , q. 2 , a. 2 ; II, d. 38 , q. 1 , a. 1 ; IV, d. 6 , q. 1 , a. 2 ; III, d. $34-35$, q. 1 , a. $4 .$. . 
La felicidad humana objetiva consiste en el último fin de la criatura. La felicidad subjetiva consiste en la posesión de la felicidad objetiva. El último fin es único y se identifica con Dios. He aquí la felicidad que los hombres apetecen según una razón de bienaventuranza y dentro de un horizonte estrictamente filosófico, esto es, Dios gozado filosóficamente y en el orden natural ${ }^{6}$. Esta es la felicidad formal y objetiva, tomada en su sentido más genuinamente riguroso, ya que existen otras formas imperfectas o parciales de felicidad, que no consideramos de momento, porque no interesan. Dios da a quien quiere, cuando quiere y como quiere objetos de felicidad imperfecta: una buena inteligencia, un buen carácter y una recta voluntad; pero estos bienes limitados no están investidos de la razón de premio o galardón, que corresponden de hecho y de derecho a una legítima bienaventuranza perfecta ?.

Así, pues: la felicidad perfecta ha de reunir conjuntamente la razón de mérito (medio) y la razón de premio (fin). En efecto, mientras estamos en la tierra, somos viadores, eternos peregrinos en marcha hacia la patria, meta final de todos los anhelos y aspiraciones del corazón humano. Tenemos fe en que un día la felicidad que ahora esperamos se nos haga presente ${ }^{8}$. Y la razón de mérito es notoria y evidente: si estuviéramos ya en posesión de esa felicidad, no habría necesidad de conquistarla, no habría necesidad de hacer algo para merecerla. No la poseemos aún, porque no es nuestra. De ahí que tengamos que alcanzarla 9. En consecuencia, la felicidad no se nos regala, sino que, en parte al menos, depende de nosotros y de los méritos adquiridos.

\section{CARACTERÍSTICAS DE LA FELICIDAD,}

Las propiedades de la felicidad son enumeradas al detalle por Tomás de Estrasburgo. No existe verdadera felicidad, si no quedan colmadas todas las potencialidades del sujeto ${ }^{10}$. La felicidad de suyo dice un "poder" ser disfrutada y gozada ${ }^{11} \mathrm{y}$, por ende, se dirige siempre a satisfacer y aquietar totalmente a la voluntad 12. Por otra parte, es de esencia de la felicidad perfecta el que sea perpetua y eterna o sempiterna ${ }^{13}$, puesto que de otro modo uno estaría siempre

6 Cfr. I, d. 34 , q. 1, a. 1; II, d. $32-33$, q. 1, a. 3 ; II, d. 4-5, q. 1, a. $4 \ldots$ Cfr. I, d. 34, q. 1, a. 1, fol. 104, col. 1 .

8 II, d. 4-5, q. 1, a. 4. Todo él muy interesante.

"Nullus meretur illud, quod suum est secundum liberam et plenariam possessionem; nam per opera meritoria acquiritur aliquid debiti in eo, quod non fuit suum" (II, d. 415, q. 1, a. 4, fol. $147 \mathrm{v}$, col. 1).

10 "Nullus autem beatus esse potest, nisi tota sua capacitas sit plene quietata, et per consequens repleta" (I, d. 17, q. 2, a. 3, fol. 76, col. 1).

11 "Ratio summae bonitatis, quae est ratio fruibilitatis" (I, d. 1, q. 3, a. 4, fol. 26 , col. 2 ).

12 "Obiectum fruibile quietat voluntatem" (I, d. 1, q. 3, a. 4, fol. 26, col. 2).

13 "De ratione actus beatifici est quod sit perpetuus" (Ibid.). 
ante la incertidumbre de su posible pérdida, siendo por lo mismo una felicidad imperfecta ${ }^{14}$. La consecuencia es lógica: Tal felicidad tiene razón de Bien sumo, viniendo incluso a identificarse con $\mathrm{El}^{15}$. En definitiva, se ha de concluir que el deseo o todo deseo del alma debe quedar plenamente satisfecho, saciado y serenado con la posesión de la felicidad final u objetiva ${ }^{16}$. Plenitud de bien, exclusión de todo mal y para siempre.

Sin embargo, no conviene que adoptemos posturas radicales y extremistas, como si la felicidad perfecta consistiera única y exclusivamente sólo en la voluntad. El hecho de que Tomás haga radicar directa e inmediatamente la felicidad plena en la voluntad no nos da derecho a excluir positivamente la presencia y la actividad del entendimiento, ya que éste ha de entrar en juego y en acción para que se logre una felicidad más completa. Incluso exige la misma unión del alma con su cuerpo para que la felicidad sea "consummata". La bienaventuranza formal consiste, sí, en un acto de la voluntad, pero asistida por el entendimiento. La voluntad es ciertamente quien se complace, pero el entendimiento, subordinado a la voluntad, es quien actualiza la visión del objeto supremo presentado a la facultad felicitaria ${ }^{17}$. Insiste machaconamente y siempre, no obstante, en la

14 "Actus enim beatificus non potest esse imperfectus" (Ibid.).

15 "Non quaelibet ratio est ratio obiecti fruibilis et beatifici; sed tantummodo ratio summi boni" (I, d. 1 , q. 3, a. 4 , fol. $26 \mathrm{v}$, col. 2 ).

16 "In perfecta beatitudine omne desiderium animae impletur et quietatur" (IV, d. 49 , q. 2 a. 1 , fol. $176 \mathrm{v}$, col. 1 ).

17 La razón objetiva, por la que puede consistir y debe consistir la felicidad formal en un acto de la voluntad, según Tomás de Argentina, radica en la primacía absoluta de la voluntad sobre el entendimiento. Es una tesis repetida y propugnada una y otra vez por nuestro autor. Consúltese la nota 5 de este artículo, que nos remite a algunos de los lugares en que el Agustino defiende pareja primacía. Todo este problema tiene una base y un fundamento más remoto: la clara distinción real entre ambas potencias racionales en la mentalidad del "Doctor facilis". Más aún: esta distinción real le mueve a aceptar y preconizar doctrinas de un fuerte impresionismo psicológico. Por ejemplo: uno mismo puede ser "beatus et damnatus" simultáneamente. ¿En qué sentido? Una facultad puede ser plenamente feliz y la otra plenamente infeliz (IV, d. 50, q. 2, Resol.). Todo ello de potencia de Dios absoluta. La voluntad puede ser feliz sin serlo el entendimiento. El entendimiento puede ser igualmente feliz sin que lo sea la voluntad. Ya en el Prólogo del libro primero defiende que Dios puede comunicar al "viador" "evidens notitia credibilium" (I, Prol., q. 3, a. 1). En el mismo libro primero pero distinción primera se plantea la siguiente cuestión: "Utrum voluntas informata caritate possit esse in actu fruitionis, intellectu manente suspenso ab omni actu cognitionis" (I, d. 1, q. 1, a. 4). Su solución es afirmativa, por lo mismo que el entendimiento no es de esencia de la voluntad: "Voluntas non dicitur appetitus intellectivus, nisi adventicie et denominatione quadam extrinseca: sed primo et per se et ab intrinseco dicitur appetitus liber, sive potentia libera". Un poco más adelante y en la misma distinción y artículo continúa: "Ad probationem dico, quod intellectum esse non est de specifica ratione voluntatis auia sine eo voluntas potest sufficienter deffiniri, puta sic. Voluntas est potentia appetitiva secundum suam naturam libera. Ex quo patet, quod esse intellectum non est intrinsecum, sed extrinsecum voluntati, et adventicium: sed esse liberum principaliter et per se est eius differentia specifica" (I, d. 1, q. 1, a. 4). 
complacencia de la voluntad ${ }^{18}$, que termina e impera las actividades iniciadas por la razón o inteligencia ${ }^{19}$.

Resumiendo, pues, podemos afirmar que la felicidad objetiva se identifica con el Sumo Bien, que por definición y esencia excluye todo mal, contiene todo bien y ambas cosas siempre y para siempre, siendo sempiterna la posesión de dicho Bien. Tal bienaventuranza objetiva y objeto beatificante tiene necesariamente que colmar todas las capacidades del sujeto. Consiste formalmente en un acto de la voluntad o si se quiere en una fruición completa y perfecta, acto propio y específico de la voluntad. Finalmente no se da ni puede darse felicidad formal plena, sin que al mismo tiempo exista en el bienaventurado la visión intuitiva por parte de la inteligencia del objeto beatífico.

\section{Deseo NATURAL DE FELICIDAD.}

Indudablemente constituye una auténtica vivencia del hombre. Todos sienten, hondísimo, un radiante deseo de felicidad. San Agustín, en múltiples ocasiones y en distintas obras, hace clara alusión a este deseo innato, clavado en el trasfondo mismo del ser humano. Dios le hizo para El. Tiene necesidad psicológica y metafísica de Dios. Su ser sólo halla reposo, quietud plena y serena, en Dios, su causa primera y su causa última ${ }^{20}$.

"Desde su nacimiento, el hombre es invitado al diálogo con Dios. Existe pura y simplemente por el amor de Dios, que lo creó, y por el amor de Dios, que lo conserva. Y sólo se puede decir que vive en la plenitud de la verdad cuando reconoce libremente ese amor y se confía por entero a su Creador" ${ }^{21}$. Diálogo consciente, libre y amoroso con Dios, eso es el hombre. "La Iglesia sabe perfectamente que su mensaje está de acuerdo con los deseos más profundos del corazón humano, devolviendo la esperanza a quienes desesperan ya de sus destinos más

18, 19 "Ad hoc, quod visio sit delectabilis, oportet quod concurrat complacentia voluntatis" (IV, d. 50, q. 1, a. 1). "Visio non beatificat, nisi concurrente complacentia voluntatis aliquo modo"; "Fruitio enim in qua essentialiter et principaliter consistit beatitudo ipsa est proprius actus voluntatis" (I, Prol., q. 3, a. 1). "Beatitudo aliquo modo consistit in actu intellectus" (IV, d. 49, q. 1, a. 2). Por tanto, la tesis queda en pie: Esencialmente la felicidad formal consiste en un acto de la voluntad, pero concomitantemente se exige también el acto del entendimiento...

20 Sobre la inquietud del Santo enunciada en Confess. $1,1,1$, PL. 32, 661, escribe el P. Turrado: "Los autores, que no perciben en esa inquietud del Hiponense su carácter radicalmente ontológico, están haciendo muy malos servicios a San Agustín y a la causa cristiana. Así lo afirma con mucha razón el célebre teólogo $H$. de Lubac en una obra reciente... Se trata de una inquietud ontológica, incrustada en el realismo del espíritu, en su conocer y amar radicales". ("Ateismo moderno y Teología”, Archivo Teológico Agustiniano 1 (1966) 62). Cfr. H. DE LUBAC, Le mystère du surnaturel, París 1965, 92...

21 Conc. Vat. II: Const. past. Gaudium et spes, n. 19, BAC, 3. ${ }^{\text {a }}$ edit. Madrid 1966, 282. 
altos... Lo único que puede llenar el corazón del hombre es aquello de "nos hiciste, Señor, para Ti y nuestro corazón está inquieto hasta que descanse en Ti" 22 Esta inquietud es el revulsivo del ser humano, flecha móvil hacia Dios y contra el Infinito. "Deseo natural de la perfección o del bien infinito, manifestado por la nunca apagada inquietud del alma humana. Nuestra voluntad oriéntase por sí misma, en virtud de una especie de lógica inmanente, hacia el Bien absoluto y hacia el Ser necesario. Sin duda, muy a menudo, nuestra acción real contradice a nuestra voluntad profunda, a esta voluntad que es en nosotros una verdadera naturaleza. Mas la insatisfacción de la conciencia, los fracasos, los decaimientos de toda especie no cesan de advertirnos de nuestros errores y de movernos a obedecer con más fidelidad a las exigencias de nuestro querer-ser fundamental. No es posible detenerse en este camino; ni los placeres, ni la ciencia, ni el arte son capaces de colmar nuestras aspiraciones a las amplitudes infinitas. Estas nos orientan irresistiblemente más allá de lo humano, más allá de todo el universo, hacia Dios, fin último, en el cual solamente puede encontrar nuestro corazón humano quietud y alegría sin mezcla de dolor" ${ }^{23}$. Esta tendencia natural hacia arriba acaso sea la gran verdad latente en el evolucionismo. Se halla larvada en la famosa teoría del "pancristismo" de Blondel, en la omegalización de Chardin, en la filosofía de la integralidad de Sciacca, en "qui est super omnia et per omnia et in omnibus" ${ }^{24}$ y en "Ut sit Deus omnia in omnibus" ${ }^{25}$ de Pablo, en doctrina de Tomás de Aquino: "Gratia... perficit tamen esse naturale" 26, "Dona gratiarum hoc modo naturae adduntur, quod non tollunt, sed magis perficiunt" 27 y "Cum enim gratia non tollat naturam, sed perficiat" ${ }^{28}$. "Oportet dicere quod gratia sit in essentia animae, perficiens ipsam", añade el santo en $D e$ Veritate, lugar citado. No se destruye con la gracia la naturaleza. Constituye una unidad con ella, elevándola, sublimándola, en un hermoso afán superador. El universo forma, tal como existe, en la actual economía de Dios, un gran sistema, un todo orgánico, que por lógica inmanente aspira más y más a trasformarse en la Divinidad. Existe una cohesión ontológica y una vinculación metafísica de todo en y con el Todo. No sólo hay una lógica inmanente. Hay una dialéctica, una interpretación, una interdependencia teal entre los componentes del mundo. Hay también una ordenación metafísica a la trascendencia. Existe un más allá a quien todo ontológicamente está naturalmente ordenado. Es correcto hablar de una necesaria coexistencia del ser creado finito y del Ser creador Infinito. El pulmón enfermo del

22 Ibid. n. 21, p. 287-8.

23. R. JoliveT, Tratado de Filosofía, III, Metafísica, Buenos Aires 1957, 348.

24 Ef. 4, 6.

$25 I$ Cor. 15,28

26 De Ver. 27, 6 ad 1.

27 In Boet. De Trin. 2, 3.

28 S. Th. 1, 1, 8 ad 2. Cfr. 1, 2, 2 ad 1; 1-2, 110, 1; IV, d. 5, q. 1, a. 3; I, d. 14, q. $3 \ldots$ 
ser limitado siente necesidad de respirar el aire puro de Dios para seguir existiendo. Aquí radica toda la profundidad del anhelo metafísico que alienta en el pecho del ser creado. No existe ni puede existir por sí. En dilacerante soledad de ser. Suplica compañía. Clama por el Otro. Tiende esencialmente hacia el Otro, de modo que sin esta exigencia metafísica no es ni ser creado, ni conservado, ni finito. El no es él y su circunstancia. Cada ser es él y Dios, que le está comunicando en todo momento su existencia, actualizando su capacidad de ser. No sé si se distingue realmente o no la esencia y existencia; pero sé que la esencia sin existencia es mero posible. $\mathrm{Y}$ a esto se reduce el ser finito sin su vinculación real a Dios. En Dios existimos. En Dios somos. Gracias a Dios. No sólo se constata un hecho. Se asienta también un derecho: La existencia sólo es posible por la inmersión del ser finito en la existencia divina, sin llegar, con todo, a la confusión y menos a la identificación de Dios y de la criatura. Son realidades física y metafísicamente distintas. Una no es otra. Una puede existir sin otra. Dios puede existir sin el ser finito, aunque éste no puede ser sin Aquel. Dios no necesita de las cosas. Son las cosas las que necesitan a Dios y de Dios. De ahí la gratuidad fundamental del ser finito en cuanto tal. No existe razón necesaria alguna de su existencia ni en Dios ni en sí. Pura liberalidad de Dios. Pura gratuidad. Pura donatividad del ser ${ }^{29}$.

Y así comprendemos, en cierto modo, la necesidad real de integrar a Dios en una auténtica concepción cosmológica y metafísica, por lo mismo que el estudio sistemático, reflexivo y crítico de lo existente conduce inexorablemente a captar la necesidad de Dios para que el mundo exista; es decir, obtenemos una especie de intuición inmediata, sin razonamientos explícitos, de las razones objetivas que fundan la existencia de Dios. Se trata de un ser inacabado e incompleto como ser, verdad, unidad, bondad, belleza..., que exige la realidad existente del Ser acabado, completo, como ser, verdad, unidad... Quizá pudiéramos también afirmar: se trata, en última instancia, de la realidad del integrismo o del integralismo total. Es decir, nada queda con sus raíces al aire. La acción divina conservadora tiene en el mundo una función esencialmente sistemática, articuladora y existenciadora. Todas las cosas, aún en su ser, dependen de las demás, especialmente del Ser a secas. Agustín asevera de los católicos que son "integritatis custodes" ${ }^{30}$. Eso mismo debe afirmarse de cada ser en particular. En su interior se recorta, necesaria y natural, una real tendencia a ser celosos vigilantes de la totalidad, de la integridad, no sólo de sí mismo, sino también de los otros. ¿Por qué todo esto? Porque la perfección de cada ser es un poco la perfección del universo $y$, por consiguiente, la perfección de los distintos seres que, de

29 A. Caturelli, La Filosofía, Madrid 1966. Cfr. Santo Tomás: S. Th. I, 25, 3, ad 3 y I, 25, 5, ad 1. Passim...

30 S. Agustín, De vera Relig., c. 5, n. 9, PL. 34, 127. 
alguna manera, entran en su constitución real. Cada ser arrastra en su marcha a los otros, con quienes está vinculado. Es una dimensión ontológica y esencial de cada ser su tendencia y exigencia y vinculación a los demás seres, sobre todo al Ser. Dios es el presupuesto metafísicamente necesario de cada ser para empezar a existir y para continuar en su existencia. Lo reclama su insuficiencia radical, su contingencia total, su negativismo de la razón suficiente de ser en sí mismo, ya que su positividad del ser consiste en el logro de esta tendencia, en la realización de este deseo, en la actualización de esta potencia metafísica. Podríamos decir que cada ser es pura funcionalidad, pura servicialidad y, mejor aún, pura apertura al Ser. ¿No es la esencia metafísica, el constitutivo formal y fundamental de todo ser finito una real religación a Dios, como profundamente defiende $\mathrm{Zu}$ biri? ${ }^{31}$. ¿No pertenece Dios a la estructura misma del ser humano y de todo ser creado? ${ }^{32}$. Entonces cada ser es una teofanía, una irradiación, es algo de Dios. ¿No dicen Tomás de Aquino y Tomás de Argentina que las cosas proceden de Dios como por "emanación"? Por eso, los seres tienden, incluso esencialmente, más y más hacia Dios, centro de todos ellos. Vienen de Dios y a Dios vuelven. Es el doble movimiento interno, natural, necesario y ontológico de los seres que no son el Ser: exigencia de apoyarse en Dios y hacerse Dios. Cada ser se mueve en virtud de una dialéctica interna e inmanente que le impulsa a su maduración mediante su arraigo mayor y más consciente en Dios. Se trata de una profunda lealtad al deseo innato y natural, enraizado en la entraña de todo ser precario, menesteroso, enfermo de suyo y contingente ${ }^{33}$. Es una confesión de fe, inconsciente desde luego, en el valor relativo y condicionado de las cosas creadas relativas y condicionadas. Se afirma el dinamismo verdadero del ser finito a trascenderse a sí mismo. No es una evasión, sino más bien una superación de sí mismo. Cada ser, de este modo, en su actividad necesaria va mucho más allá de su estructura individualista. ¿No nos habla San Agustín de una confluencia humana en Dios? ${ }^{34}$. Por esta ordenación metafísica de las cosas a Dios, nos explicamos que un mayor conocimiento de las cosas pueda ser un mayor conocimiento de Dios, como afirma San Pablo: "Desde la creación del mundo, lo invisible de Dios, su eterno poder y su divinidad, se alcanzan a conocer por las criaturas" ${ }^{35}$. $\mathrm{Si}$, pues, las cosas tienden natural y necesariamente hacia Dios, lógicamente nos llevarán de suyo a Dios. "El alma humana gira en Dios como los planetas en el

31 X. ZubrRI, Naturaleza, Historia, Dios. En torno al problema de Dios, Madrid 1946.

32 J. Courtney MURRay, Le problème de Dieu de la Bible a l'incroyance contemporaine, París 1965. En la página 104 escribe: “Dieu, même s'il n'est pas reconnu, ne cesse d'appartenir à la estructure de l'existence humaine".

33. A. FOREST, Du consentement a l'etre, París 1936.

34 Confess. XI, 29, 39, PL. 32, 825.

35 Rom., 19, 23. 
cielo" ${ }^{36}$. "Sólo se encuentra el reposo del espíritu en lo absoluto, el del sentimiento en el infinito y el del alma en lo divino" 37.

Aquí, sin embargo, radica la gran tragedia y dramatismo de la existencia humana: ¡Es posible la bancarrota de su destino! ¡El hombre esencialmente es un ser ontológicamente anclado en Dios. Pero el hombre psicológica y conscientemente puede instalar su deseo y aún su ser en objetos que no dan la felicidad completa al corazón humano, desbordado casi siempre de inquietudes nunca plenamente satisfechas! ¿Por qué el hombre ha de ser así? ¿Vive el hombre siempre pendiente de su felicidad? ¿Puede vivir en una constante fuga de su auténtica felicidad? ${ }^{38}$. Busca en todo instante su felicidad. Mas la sitúa donde no se halla ni puede hallarse. He ahí la raíz última de su angustia vital, de su profundo desequilibrio psicológico, de su náusea metafísica, de su sentimiento trágico, de su vida rota y desgarrada, de su alma en sangre y de su corazón en tensión. ¡Qué elocuente se muestra en esto la moderna Filosofía: Kierkegaard, Richter, Nietzsche, Unamuno, Heidegger, Sartre, Camus, MerleauPonty...! Rotas las amarras con Dios, sólo queda el acantilado hueco de la nada.

Tomás formula así el problema: ¿Es la felicidad objeto natural del deseo de todo hombre? ¿Ama todo hombre la felicidad? ¿Consciente o inconscientemente, es decir, de modo consciente o de modo inconsciente?

Como se ve, el problema es vital, ya que encierra en germen toda la problemática del corazón humano y los principios más sólidos de la psicología, de la metafísica y de la ética, incluso el presente y el futuro del hombre. Más aún: este problema da un sentido profundo a las preguntas eternas que siempre han atormentado, en sus raíces, la estructura misma del ser humano: ¿Qué es el hombre? ¿Qué sentido tiene la vida? ¿Qué valor tiene la actividad humana? ¿Qué hay después de la vida temporal? ${ }^{39 !}$.

Nuestra tarea va a consistir en captar el pensamiento auténtico de Tomás de Estrasburgo. No es tarea, desde luego, del todo fácil. Sin embargo, no es tampoco del todo imposible. Para mayor claridad afrontaremos el problema desde dos ángulos de vista distintos: a) Plano metafísico. b) Plano psicológico. De esta forma queda completa la mente del autor.

36 H.-F. AMIEL, Journal intime, 7 de abril de 1850.

37 Ibid., 18 de noviembre de 1851.

38 P. Rostenne, "Pour une metaphysique de l'Amour": Giornale di Metafisica 21 (1966) 242, donde escribe: "Il est tragique pour l'homme de pouvoir être sensible a la présence de Dieu sans la reconnaître explicitement. C'est ce qui le rend capable de tant déceptions... Aimer Dieu ou à sombrer dans le désespoir...". "Pudeat autem, cum alia non amentur nisi quia bona sunt, eis inhaerendo non amare bonum ipsum unde bona sunt" (De Trin. 8, 3, PL. 42, 950).

39 Conc. Vat. II: Const. past. Gaudium et Spes, n. 10-11, BAC, 3. ${ }^{\mathrm{a}}$ ed., Madrid 1966, 272, 274. 
a) Plano metafísico.-Nuestra previa confesión se reduce a constatar que Tomás de Argentina no plantea de forma consciente y sistemática y aposta el problema. En ninguna de sus muchas distinciones y cuestiones ataca de frente el tema discutido. No obstante, podemos afirmar que lo da por supuesto, que se halla sobreentendido en diferentes lugares de su egregio Comentario al Libro de las Sentencias. Trataremos, pues, de estructurar su pensamiento, en cuanto sea posible, valiéndonos de las distintas premisas establecidas a lo largo de su obra. Ya sé que muchas de estas premisas son suscritas por todo verdadero filósofo cristiano. Tanto mejor. Nosotros, pues, las contemplatemos aquí y procuraremos lógicamente sacar las conclusiones necesariamente implicadas en las mismas. Creemos que no forzamos la marcha del pensamiento de nuestro autor.

Corriendo el riesgo y aceptándolo, nos esforzaremos por dar en forma breve y sintética las líneas fundamentales del pensamiento del Agustino. Para proceder con lógica, honradamente vamos a preguntar: ¿Admitió Tomás de Argentina un deseo innato, radicado en la misma alma, de Dios como objeto beatificante? ¿Hay una tendencia natural en el ser creado y, por ende, en el ser humano hacia Dios? ¿Pertenece, en cierto modo, Dios a la estructura de la existencia humana? ¿De toda existencia creada?

La respuesta a estas preguntas, quizá, deba ser afirmativa, de acuerdo con doctrinas defendidas o presupuestas en su Comentario. ¿En qué nos fundamos para inclinarnos por la contestación positiva? Varios son los fundamentos que sirven de apoyo a esta tesis. En gracia de la brevedad, los vamos a resumir al máximo:

1. ${ }^{\circ}$ Toda criatura, en cuanto criatura, es una pura referencia a Dios. Todo ser está ordenado a Dios. Es más: consiste en estar ordenado a Dios. Se trata de un orden real: de una dependencia total. Los textos claros a este respecto se hallan multiplicados hasta la saciedad. Copiaré algunos literalmente: "Omnis creatura realiter refertur ad Deum" ${ }^{40}$. "Creatura realiter dependet a Deo et ad ipsum ordinatur" ${ }^{41}$. Y así otros más.

2. En segundo lugar conviene tener en cuenta el concepto de Tomás de Argentina sobre la relación. Toda relación es cierto orden: es ser para: es un modo de ser frente a algo distinto: pura referibilidad: "quidem ordo", "modus essendi ad aliud", "esse ad aliud" 42 . Es doctrina común en la Escolástica, heredada de Aristóteles.

3. La relación, pues, carece de "inseidad". Consiste en pura "adaleidad". La palabra es tosca, pero muy expresiva. Queda, por tanto, en pie. Tomás de Argentina concibe la relación como algo dinámico, como un caminar, como una

40 I, d. 30 , q. 1, a. 2.

41 I, d. 30 , q. 1 , a. 3.

42 II, d. 20 , q. 1, a. 2. 
tendencia. Pero como una tendencia, además, instalada en la existencia de la creatura. No debemos perder de vista que el autor defiende que el efecto de la creación, efecto inmediato y directo, es la existencia: el esse, que es dinámico, que es acto, que es vida ${ }^{43}$. El estrato no puede ser más metafísico. Tendencia radicada en la misma existencia del ser. También del ser humano, en consecuencia. "Formaliter et quidditative dicit solum tendentiam ad aliud" 44.

4. ${ }^{\circ}$ Apliquemos esta doctrina a la criatura y a Dios. El resultado es positivo: "La relación de la criatura al mismo Dios es algo real que existe en la criatura, en virtud de lo cual ésta está ordenada a Dios" ${ }^{45}$. No es sólo esto. Se trata de una relación natural, por lo mismo que todo el ser natural de la criatura depende de Dios ${ }^{46}$. Todo su ser, ya absoluto, ya relativo, la criatura lo tiene recibido de Dios ${ }^{47}$. Toda criatura fundamentalmente se halla orientada a Dios por su misma naturaleza, si bien lo está formalmente por la misma relación, que es algo real en ella ${ }^{48}$.

La conclusión, pues, se impone. Toda criatura dice un orden real a Dios. Toda criatura es una relación real a Dios. Pero ¿no es la relación, según el autor, una tendencia real hacia su término? Por tanto, toda criatura tiende realmente hacia Dios, fundamentalmente en virtud de su misma naturaleza y formalmente en virtud de la misma relación. Expresamente lo afirma Tomás de Argentina cuando escribe: "Quamvis inter creatorem et creaturam non sit medium tale, quod nec sit creator nec creatura; tamen inter creaturam absolutam et creatorem per modum cuiusdam tendentiae mediat creatura, quale est relatio: quae cum sit ipsa tendentia, sive ordo, non requirit aliam tendentiam mediam, sed seipsa tendit ad terminum" 49 .

Ahora bien: ¿No es el hombre una criatura? Será, pues, una relación real a Dios. Existirá en su entraña una tendencia real hacia Dios, como su término, que es decir como su último fin. Pero esta criatura es un espíritu racional y como tal obra. ¿Tender realmente hacia Dios no es desearle naturalmente? ¿No equivale a tener apetito real, ontológico y metafísico de Dios? ¿No es esto lo que quiere decir un autor moderno cuando escribe: Il faudra que l'aimantation essentielle de l'homme à Dieu soit una aimantation amoureuse? ${ }^{50}$. Existe una atracción de Dios ejercida sobre la criatura. Sin Dios el hombre se halla inquieto. No halla el reposo anhelado. Sólo el deseo y el amor llevan a Dios. Sólo la satisfacción del deseo de Dios y su amor ordenado reporta paz y reposo al alma, al ser mismo del hombre. Profundamente escribe el mismo Paul Rostenne: "L'amour signifie la possibilité pour l'homme d'être touché par l'authentique transcendance de l'Etre

43 II, d. 19, q. 1, a. 1.

44 II, d. 20 , q. 1 , a. 2 .

$45,46,47,48,49$ I, d. 30 , q. 1 , a. 3 y 4

50 P. Rostenne, "Pour une Metaphysique de l'Amour": Giornale di Meta. fisica 21 (1966) 239. 
présente à tout ce qu'est en tant qu'il est" ${ }^{51}$. Es la tremenda capacidad real del hombre. En su horizonte metafísico se abre una ventana a la trascendencia. Pero el hombre es libre y puede cerrar la ventana o mirar hacia otra parte. Puede volver la espalda a Dios. Puede convertirse en creador de pequeños dioses, poniendo su corazón en las cosas o concediéndoles un rango que no tienen ni pueden tener. ¿No ha creado el hombre el ídolo de la ciencia, del progreso, de la técnica, en los tiempos modernos? ¿No es cierto que en todo tiempo, para la mayoría de las personas, las riquezas, el dinero, la economía, los dividendos han sido su único ídolo? ¿No ha convertido en Dios algún filósofo de nuestros días incluso a la misma nada? Pero aún en su misma impotencia real hierve una idéntica pasión: pasión de ser Dios: hambre de ser más, de ser Dios. ¡Tan radical es la necesidad de trascendencia sentida en el mismo corazón del ser humano! Pura relación a Dios, tendencia real hacia Dios, deseo natural e innato al ser humano, expresiones distintas, pero contenidos idénticos. ¿No responde a esta angustia vital ante la insuficiencia de las cosas el grito ensangrentado de Agustín: Nos hiciste, Señor, para Ti e inquieto está nuestro corazón hasta que descanse en Ti? ${ }^{52}$.

Concluímos, pues: en el seno mismo de toda criatura y, por lo mismo, del hombre, existe un deseo natural y una tendencia real hacia Dios, según Tomás de Argentina.

5. Por otra parte, acaso pudiéramos ahondar en esta materia aún más, sobre todo si tenemos en cuenta las repetidas veces que cita el texto ya clásico de San Agustín, líneas atrás referido. Nuestro autor hace uso del mismo en diversos lugares y desde perspectivas distintas. Cinco veces al menos lo cita con las mismas palabras del Santo, aunque un poco invertido su orden: Ad te nos fecisti, Domine, et inquietum est cor nostrum donec requiescat in te. $\mathrm{Y}$ es curioso: en todas las citas parece que admite el valor del texto. Da por supuesta su verdad interna. ¿Por qué, de otro modo, concluye categóricamente: "ergo non potest cor nostrum beatifice quiescere in aliqua creatura?" 53 No: el corazón del hombre no halla su descanso en las criaturas. En otra parte nos plantea el autor el siguiente problema: ¿ el objeto fruíble o beatificante ha de saciar plenamente al alma racional en cuanto a "totum suum desiderium"? ${ }^{54}$. Y acto seguido aplica el texto de Agustín. Quede constancia: habla del alma racional y de su deseo total. ¿No implica todo esto una dimensión profundamente ontológica? ¿No se refiere a un deseo innato y radical del alma humana? Tanto más que en el mismo lugar, cuestión segunda y conclusión primera, acepta toda una serie de frases, muy significativas a nuestro respecto, todas de San Agustín: "Natura compellit omnes

\footnotetext{
51 Ibid. 242.

52 Confess. 1, 1, 1, PL. 32, 661.

53 III, d. 14 , q. 1 , a. 1.

54 I, d. 1 , q. 1, a. 1 .
} 
ad volendum beatitudinem et immortalitatem: quia omnes interrogati respondent statim ista se velle" ${ }^{55}$. "Hoc veritas clamat et natura compellit, quam summe bonus et immutabilis creator indidit" "56. ¿No se trata de un deseo natural? ¿De un deseo innato? ¿No usa el verbo "indidit"?

En otra parte 57 se pregunta si podemos conocer la esencia de Dios, si podemos tener naturalmente un conocimiento quiditativo de la esencia divina: Su postura es negativa: contando con las solas fuerzas naturales de la razón no hay posibilidad de conocer quiditativamente la "deidad". ¿No hay dificultades? He aquí una grave: No existen deseos naturales imposibles. Pero existe en el hombre un deseo natural de conocer la esencia de Dios. La prueba se reduce al texto de Agustín: "Nos hiciste, Señor, para Ti e inquieto está nuestro corazón hasta que descanse en Ti". No obstante la objeción, Tomás de Argentina permanece impávido. No niega que exista semejante deseo natural. Tampoco niega que el Hiponense quiera expresarlo con su famoso texto, de cuya verdad ni siquiera duda. Tan sólo ataca la afirmación de que no existen ni pueden existir deseos naturales imposibles: acude a la experiencia personal de cada uno: "Naturaliter nos desideramus non mori: quod patet: quia dequali necessitate desideramus fugam mali nocivi et prosecutionem boni proficui: sed naturaliter unumquodque appetit esse et non potest appetere non esse... et tamen impossibile est rem corruptibilem non corrumpi quantum est ex parte sui" ${ }^{58}$. ¿Elocuente la actitud mental de Tomás de Estrasburgo? Sin duda. Un deseo natural, en cuanto mero deseo natural, puede frustarse. Es decir, no se puede establecer la existencia de Dios inmediatamente a partir del deseo natural del alma hacia la felicidad infinita. Por tanto, para que ese texto esté revestido de validez desde un punto de vista metafísico se impone necesariamente que se le interprete de forma más radical, captando su dimensión más profunda. Es decir, debe expresar la insuficiencia intrínseca del ser finito, debe significar la contingencia total del ser humano. De este modo acaso pueda constituir un auténtico punto de partida para elaborar una verdadera demostración que reclame la existencia de un Ser que colme sus deseos, porque es plenitud de Bien. Mas ¿por qué esta tendencia natural a Dios? Porque es el último fin extrínseco de toda criatura, que satisface todos sus deseos y llena su esperanza. Dios es el supremo Bien. Por esto, el alma tiende necesariamente hacia El. De ahí

55, 56 El autor no cita exactamente a Agustín. Es más, le da una versión al Santo muy profunda. En el fondo, interpreta y acepta. Incluso, el primer texto no pertenece al lib. 8 De Trinitate. Pertenece al libro 13. Escribe Agustín: "Cum ergo beati esse omnes homines velint..., profecto et esse immortales volunt: aliter enim beati esse non possent. Denique et de immortalitate, interrogati, sicut et de beatitudine, omnes eam se velle respondent" (De Trint. 13, 8, PL. 42, 1.022). El otro texto en San Agustín es: "Aut si volunt, ut veritas clamat, ut natura compellit, cui summe bonus et immutabiliter beatus Creator indidit hoc" (De Trinit. 13, 8, PL. 42, 1.023).

57 I, d. 3, q. 1, a. 2.

58 I, d. 3, q. 1, a. 2 , 
también que fuera de Dios el corazón humano siempre se halla torturado por la inquietud ${ }^{59}$.

Todo esto me parece bastante coherente. Late la misma verdad: el hombre se halla en tensión hacia Dios, que es quien puede colmar y calmar su ardiente sed de felicidad. ¿Podremos, pues, hablar con cierto fundamento de un deseo innato y natural del hombre hacia Dios? ¿No podremos afirmar que todo hombre tiende de modo necesario y natural a su felicidad plena, a su bondad final, que, en el fondo, no es sino Dios? ¿No viene y está implícito en la dialéctica interna del ser humano, del mismo conocimiento humano? Tendemos hacia el bien finito consciente e inconscientemente. Mas ¿no es verdad que siempre podemos pensar un bien mayor? ¿Cómo puede un bien inferior concebido como menor llenar la inmensa capacidad de deseo, inserto en el corazón del ser humano? Sí, siempre queremos más, siempre aspiramos a más, hasta que gocemos totalmente del bien pleno, de Dios.

Por tanto, sin violentar mucho los textos de Tomás de Argentina, no resulta incorrecto concluir la existencia de un deseo natural e innato que emerge, inexorable, en el núcleo mismo del ser humano.

b) Plano psicológico.-En este plano es donde propiamente se sitúa nuestro autor. Lo expuesto anteriormente lo hemos ido hilvanando al través de textos y más textos del agustino. Pero desde esta perspectiva psicológica Tomás de Estrasburgo habla con entera claridad, sintetizando su pensamiento en dos netas conclusiones ${ }^{60}$ :

Primera conclusión: El hombre desea naturalmente la felicidad, cuando la considera actualmente y de forma debida. Pero es menester que haya un pensamiento actual, una conciencia de él; y es menester que el pensamiento sea recto, de acuerdo con la verdad. No basta una pseudo-idea o un pseudo-pensamiento, sino que el hombre ha de darse cuenta del objeto beatífico. Cuando estima críticamente su felicidad, al pensar actualmente en ella, nace naturalmente en su corazón la tendencia hacia la misma. Pueden darse sujetos anormales, anómalos, pero esos no se contemplan. Se supone un hombre normal. Tomás emplea el adverbio "recte" aplicado al verbo "considerans". Un hombre harmónico piensa en su felicidad y la desea. La dialéctica de este deseo brota de la esencia de la voluntad, como facultad de bien. Al Bien sumo lo amará sumamente, que es su felicidad ${ }^{61}$.

59 IV, d. 49 , q. 3 , a. 1.

60 "Omnis homo actualiter recte considerans, quid importatur nomine beatitudinis, naturaliter appetit beatitudinem" (IV, d. 49, q. 3, a. 3). Como buen escolástico el autor plantea formalmente la cuestión, situando al sujeto en una consciencia clara de la felicidad. Pero ¿no desea la felicidad quien no piensa en ella? ¿No se da un deseo habitual de la misma?

61 "Omnis homo, qui actualiter considerat tale bonum, quo habito habetur sufficientia omnis boni, ille naturaliter appetit huiusmodi bonum: Sed quicum- 
Todo ser ama su perfección, su unidad, su existencia..., hasta donde es posible al diapasón de su esencia. Todo ente propende necesaria y religiosamente a conservar su ser a tono con su ciclo vital y esencial. Podemos, pues, decir que el hombre no es una estridencia en la armonía perfecta del universo. El también tiende necesariamente hacia lo que es su Bien pleno ${ }^{62}$.

Por tanto, el conocimiento actual de la felicidad siempre provoca en el hombre el deseo natural de la misma. ¿En virtud de qué no había de desearla? $¿$ No es esencial al apetito racional desear el bien? ¿No es la felicidad el mayor bien de la voluntad por cuanto implica la plenitud de todo bien? ¿No sería contradictorio que la voluntad humana no desease aquello que es su propio objeto, es decir, su Bien? ¿No equivaldría ello a injertar el absurdo en el corazón de su mismo ser? ¿A qué se reduciría entonces el orden interno de la voluntad? ¿A qué leyes intrínsecas y necesarias responderían la génesis y la maduración de sus actos? ¿Estarían presididos por las leyes del "capricho", de la "necesidad fatalista", del "logos interno" a su esencia?

Por exigencia, pues, de los mismos principios de contradicción, de identidad, de razón suficiente y de finalidad, el hombre instintivamente quiere la felicidad cuando piensa de hecho en ella. La "logicidad" (de "logos", sentido, estructura) del ser humano, microcosmos, síntesis de alma y de cuerpo, por tanto racionalidad, postula cierta coherencia en el despliegue de sí mismo y de sus actividades.

SEgunda CONCLusión: A estas alturas se perfila una nueva dimensión del problema. ¿Cómo desea el hombre la felicidad? ¿De modo necesario o de modo libre?

A los interrogantes abiertos responde la segunda conclusión del egregio teólogo y filósofo agustino:

que actualiter recte considerat illud, quod importatur nomine beatitudinis, ille actualiter apprehendit tale bonum, quo habito habetur sufficientia omnis boni: ergo..." (IV, d. 49, q. 3, a. 3, fol. 204v, col. 2). "Purum bonum clare visum et aperte monstratum voluntati, voluntas nullatenus potest odire: immo necessario ipsum amaret amore naturali" (IV, d. 50, q. 2, Resol., fol. 220v, col. 2). "Per desiderium, quod est quidam actus voluntatis, movemur ad Deum" (I, d. 1, q. 1, a. 3 , fol. 21 , col. 1). "Ostensa beatitudine, sive ultimo fine ipsi voluntati, voluntas naturaliter amat et desiderat ipsam" (I, d. 1, q. 2, a. 1, fol. 21v, col. 2). "Praesentatum per intellectum voluntati sub ratione summi boni, omni carens defectu, ab ipsa voluntate non potest refutari" (I. d. 1, q. 2, concl., 1; fol. , col. 1). "Summum bonum etiam in via apprehensum in universali necessitat voluntatem necessitate immutabilitatis" (I, d. 1, q. 2, concl. 3).

"Quilibet naturaliter desiderat illud, in quo eius summa consistit perfectio, iucunditas, commoditas et delectatio: Sed in tali bono, quo habito habetur sufficientia omnis boni, consistit hominis summa perfectio..." (Ibid.).

62 "Inquirens veritatem circa finis speculationem, non semper apprehendit ultimum finem...; pro quocumque enim tempore sic iudicat de ipso, necessario appetit ipsum, et pro tunc non potest ipsum non amare" (I, d. 1, q. 2, a. 1, fol, $22 \mathrm{v}$, col. 2). 
"Todo hombre que considera actual y adecuadamente la felicidad, la desea de modo necesario" 63 .

No sólo, pues, desea el hombre la felicidad cuando piensa en ella, sino que, además, la desea necesariamente. No puede no amarla. No puede no desearla. En conformidad con la primera conclusión, existe una absoluta sincronía entre la capacidad desiderativa de la voluntad y la capacidad satisfactiva de la felicidad. No se ve razón, por tanto, para no desearla y amarla, ya que constituye la perfección, el orden y el descanso del mismo apetito. ¿Acaso puede desear "ex se" el apetito, que es esencialmente una tendencia, otra cosa que la aquietación y la satisfacción de sí mismo?

Escribe Tomás de Argentina: Nadie puede dejar de apetecer su máxima perfección. Pues bien: la máxima perfección consiste en la felicidad. Nadie puede dejar de apetecer la felicidad ${ }^{64}$.

Nos hallamos en el cogollo mismo de la razón anterior. Todo conocimiento del bien provoca una inclinación, ejerciendo una fuerte atracción sobre el apetito y concitando un ardoroso afán de captación. En la medida en que es bien en sí o bien pleno y se estima como tal, en esa misma medida suscita la vivacidad o viveza del deseo. ¿Constituye ese bien la felicidad objetiva, llegando a indentificarse con ella? Fluitá un deseo inexorable, necesario e indeclinable, como es necesaria, inexorable e indeclinable la tendencia del hombre hacia su perfección suprema. Pero ¿ no es cierto y evidentísimo que la felicidad objetiva es de suyo plenitud de todo bien, eliminación de todo mal, todo ello para siempre? ${ }^{65}$. Nadie desea el mal que es sólo mal ni puede amarlo, sea mal real o aparente. La razón del mal es repulsiva. No atrae. Aleja. Al revés, el bien que es sólo bien ¿no

63. "Quicumque praedicto modo considerat: seu apprehendit beatitudinem, ille necessario appetit eam" (IV, d. 49, q. 3, a. 3). "Quod pro statu viae obiecto fruibili apprehenso per intellectum sub ratione ultimi finis, de necessitate fruitur eo fruitione viae" (I, d. 1, q. 2, concl. 1). "Omnis virtus appetitiva necessario videtur appetere id, in quo consistit summa eius perfectio, maxime cum id actualiter fuerit sibi ostensum" (Ibid.). "Actus qui est alicui potentiae simpliciter naturalis, ut sic est sibi simpliciter necessarius: sed ostensa beatitudine, sive ultimo fine ipsi voluntati, voluntas naturaliter amat et desiderat ipsam...". "Si.. cut id, quod est malum realiter et apparenter, se habet ad prosecutionem; sic id, quod est bonum realiter et apparenter, se habet ad refutationem: sed illud nullatenus potest desiderari: ergo istud nullatenus potest refutari: sed obiectum fruibile est bonum realiter et apparenter" (Ibid.). "Illud, participatione cuius voluntas vult omne, quod vult, illud non potest voluntas non velle: ultimus finis, seu obiectum fruibile est huiusmodi" (Ibid.). Y así toda esta distinción se halla salpicada de textos que demuestran o tratan de demostrar la conclusión asentada por el autor...

64 "Nullus potest non appetere illud, in quo consistit summa eius perfectio, iucunditas, commoditas et delectatio: sed omnia ista veraciter consistunt in beatitudine: ergo..." (IV, d. 49, q. 3, a. 3). Cfr. las notas siguientes de este artículo: $60,61,62,63$.

65 "Beatitudo omne bonum hominis includit, vel essentialiter, vel saltem concomitanter" (IV, d. 49, q. 3, a. 3). Cfr. notas: 9, 10, 11, 12, 13, 14, 15 y 16, ya que ellas suponen esta plenitud de bien, esencial a la felicidad, a toda felicidad. 
atraerá de modo necesario? ¿No es el último fin la razón por qué amamos y deseamos todo lo demás? ¿No vienen a ser una y misma cosa el último fin y el sumo Bien? La tendencia al bien es natural, incrustada en la intimidad de todo ser. ¿No tenderá entonces la voluntad hacia la felicidad objetiva y esto de modo necesario y más teniendo en cuenta que es su auténtico bien y perfección?

Por tanto, el hombre, todo hombre desea y ama necesariamente la felicidad objetiva.

PROBlematicidad De SOLUCión.

Todo esto parece luminoso, con evidencia casi inmediata. ¿Es efectivamente así? ¿No existen serias dificultades contra la doctrina y solución de Tomás? Si todo hombre desea y ama natural y necesariamente la felicidad, ¿qué merito hay en ello? Este deseo y amor a la felicidad, apremiante e imperioso, ¿puede ser fuente y raíz de mérito para el hombre? En lo que no se puede evitar, ¿qué responsabilidad e imputabilidad puede haber?

Por otra parte, si el deseo y el amor a la felicidad es natural y necesario, ¿Cómo es que el hombre deja a veces de pensar en ella? ¿Por qué el entendimiento no considera de hecho siempre la felicidad propia y específica del hombre? ¿Cómo permite la voluntad esas "distracciones" al entendimiento?

Además, se afirma que el deseo y el amor a la felicidad es natural e incluso necesario. ¿Puede un deseo natural y necesario ser vano, inútil o superfluo, de modo que no consiga su fin? ¿Qué pasa entonces con los condenados? ¿Qué con los niños que mueren sin bautismo? ¿A qué se reduce en ellos el deseo natural y necesario?

\section{APORETISMO DEL MÉRITO.}

Ante todo conviene establecer una pequeña distinción. Algo puede ser natural de varias maneras. Es natural que un hombre sin fantasía o con el cerebro destrozado no sepa nada. Hay cosas naturales que no dependen en absoluto del hombre, ni en su ser, ni en sus causas, ni en sus principios constitutivos. Pero hay cosas que son naturales $y$, sin embargo, dependen, al menos en sus causas, del hombre. Es natural que un hombre borracho realice tonterías y diga sandeces. Estas son efecto natural de la borrachera, que estuvo en nuestras manos evitarla. En las cosas naturales, según el primer modo, ni hay mérito ni demérito, ni alabanza ni vituperio. Mas ¿ por qué no podrá haber mérito en las cosas verificadas de acuerdo con el segundo modo de ser natural? ¿Qué contradicción hay en ello? ¿No estuvo en poder del hombre hacer tal cosa o tal otra? ¿No nos hacemos 
responsables de los efectos que se siguen o pueden seguirse de esas causas, embriaguez, por ejemplo, de modo natural? ${ }^{66}$.

Apliquemos esta doctrina a nuestro caso. El deseo y el amor a la felicidad no es natural según el primer modo. Sí lo es a tono con el segundo modo. ¿De qué suerte? La causa del deseo de felicidad es la consideración actual sobre la misma. Ahora bien: esta consideración en parte es facultativa del hombre, sometida de alguna manera al imperio de la voluntad y al control de la misma. El hombre puede así pensar en otras muchas cosas más. En cierto modo, pues, el pensamiento actual sobre la felicidad depende del sujeto, que desea naturalmente su bienaventuranza. ¿Por qué no podría haber aquí una posible razón de posible mérito o de posible demérito? ${ }^{67}$.

No se arranca, por consiguiente, de raíz la fuente del mérito, ya que la consideración actual o no consideración actual de la felicidad está bajo nuestro control y en nuestro poder y dominio. Se puede de hecho pensar en la felicidad objetiva o en la desintegración del átomo o en la estructura de la litosfera. No. está uno incoerciblemente forzado y necesitado a pensar en el objeto felicitario en todos y cada uno de los segundos de la existencia. El hecho de pensar en la felicidad, parcialmente al menos, es libre. Se piensa en el objeto que hace feliz porque así lo quiere la voluntad, que es dueña de desviar la atención del mismo cuando quiera y como quiera.

66 "Aliquid esse naturale potest dupliciter intelligi. Uno modo, simpliciter et pure, sicut illud, quod nec secundum se, nec secundum suas causas et principia est in hominis potestate... Alio modo, non simpliciter, puta, quando aliquid pro tunc inevitabiliter adest homini, cuius tamen causas, si voluisset et debite attendisset, potuit praevenire. Circa naturalia primo modo, nec est laus, nec vituperium, nec meritum, nec demeritum: haec tamen bene possunt esse circa naturalia secundo modo dicta" (IV, d. 49, q. 3, a. 3).

67 "Desiderium beatitudinis est naturale secundo modo... Actualis enim consideratio de beatitudine est causa aliquo modo sui desiderii, et huiusmodi consideratio est in potestate ipsius hominis: posset enim homo alia considerare, se vellet, et per consequens, non haberet actum elicitum circa hoc obiectum, quod est beatitudo, quamvis naturaliter desideret eam: etiam actu elicito, supposito, quod actualiter consideret eam. Ideo bonus homo, qui voluntarie sequestrat suam considerationem de aliis rebus, et tota devotione considerat, qualis et quanta est beatitudo, quam nobis daturus est Deus, in desiderio beatitudinis multum potesi mereri. Etiam potest dici quod non excludit omnem libertatem, sicut est in proposito, quia desiderium beatitudinis, quamvis excludat libertatem contradictionis, tamen non excludit libertatem affectuosae complacentiae, quae stat cum immuta. bilitatis necessitate" (Ibid.).

"Voluntas non semper habet plenum posse super remotionem illius prohibentis: quia non est in potestate nostra... Etiam corporalis nostra necessitas nos cogit considerare quandoque de aliis, quam de ultimo fine... A phantasmatibus vario modo immutatur noster intellectus, nec est in potestate nostra... Etiam necessitatis corporalis inedia, de multis aliis, quam de ultimo fine, nos saepe cogitare compellit" (I, d. 1, q. 2, concl. 1). Ambos textos resultan de gran importancia por sus fértiles aplicaciones al orden moral. ¿No es cierto que de este modo queda a veces reducida la responsabilidad de ciertos actos, no obstante que el entendimiento vea clara su malicia? ¿No es cierto que no siempre hacemos aquello que ve como bueno la razón y esto con más o menos libertad o voluntariedad? La cuestión queda fiotante... 
Por lo demás, ¿por qué no podría existir mérito en querer de hecho lo que la razón estima como felicidad objetiva, aún cuando hubiese error en su apreciación? El conocimiento dispara naturalmente la tendencia hacia la felicidad un poco necesariamente. Mas todo esto encaja perfectamente y está de acuerdo con la naturaleza humana. Todo ello no dobla ni quiebra la dialéctica internạ del ser libre del hombre. De seguida hace acto de presencia una mayor toma de conciencia. Uno se da más cuenta, por un nuevo acto reflejo, de que en él emana el deseo natural y necesario de la felicidad. ¿Por qué no podrá haber mérito en este querer y desear más reflexivo y más consciente? ¿No depende acaso del hombre su actual consideración para ver más claro y para mejor captar su objeto en toda su verdad y bondad?

Quizá sea conveniente distinguir entre un conocimiento perfecto, comprensivo y esencial de la felicidad y un conocimiento imperfecto, más o menos esencial y analógico ${ }^{68}$. A tenor de esta distinción acaso se pueda decir que el conocimiento perfecto causa necesariamente el deseo idóneo de la felicidad. Los argumentos de Tomás serían entonces aplicables a este conocimiento. Mas ¿quién posee de hecho, mientras es viador o viandante, un conocimiento quiditativo y perfectísimo de la felicidad? De ahí la posibilidad, siendo todavía peregrino hacia al patria, de conducirse al margen de la misma. Aún desde una perspectiva humana filosófica y teológica, ¿qué otra cosa viene a ser el pecado? ¿No es en cierto modo el rechazo consciente de la felicidad objetiva? Somos conscientes de que nuestra concepción ética identifica la felicidad objetiva con Dios. ¿Ama el hombre siempre a Dios, ni aún cuando piensa en El? De esto se infiere que podemos evidentemente dejar de desear la felicidad, porque podemos dejar de pensar en ella ${ }^{69}$.

Tampoco debemos perder de vista que hasta el mismo deseo es susceptible de diversas matizaciones. Puede ser eficaz: exige que se piense también en los medios aptos para la consecución del fin pretendido. Puede ser simple deseo: no exige la consideración de los medios. Puede ser deseo condicional: depende de una condición: quisiéramos volar, si nos fuera viable ${ }^{70}$.

Como es fácil comprender, no interesa el tercer modo de desear algo. Sí interesan los dos modos primeros. El segundo brota inmediato a todo conocimiento de felicidad objetiva. En éste acaso no haya mérito, porque es espontáneo, automático, nos sale del alma. Sólo se piensa en la felicidad: no hay deliberación,

68 No hacemos idealismos ficticios con estas distinciones, pues el autor habla. de "intelligere non pleno, sed semipleno", de "intelligere habituali et semipleno" y de "intelligere actuali et pleno" (IV, d. 50, q. 1, a. 1).

69 "Desiderium beatitudinis possumus vitare: quia possumus de ipso non considerare" (IV, d. 49, q. 3, a. 3).

70 "Tripliciter potest quis appetere aliquid, seu considerare: Uno modo desiderio efficaci, puta quando sic considerat, quod etiam cogitet media, per quae possit consequi ipsum desideratum. Alio modo desiderio simplici, puta sine cogitatione huiusmodi mediorum. Tertio modo conditionali, puta quandoque homn appetit, si esset possibile, quod libenter vellet volare" (Ibid.). 
contraste de pros y de contras. No sucede así en el primero. Aquí es posible el mérito, pues implica una reflexión más espaciada y más profunda. Ya entraña, sin duda, un esfuerzo, una ascética disciplinar y sostenida de la voluntad que impone a la mente el seguir pensando. $\mathrm{Y}$ a este conocimiento más consciente y más personal sigue naturalmente un deseo que pone en marcha la biología para satisfacerlo. Tras una meditación seria y atenta, pone en práctica los medios precisos para su consecución. ¿Por qué no podría haber mérito en todo este andamiaje espiritual, fruto de una fuerte tensión del alma y de la voluntad? ¿No se ha procedido libremente en la profundización de la felicidad objetiva y en la investigación y hallazgo de los medios que llevan a la misma? ¿No es suficiente que los actos sean libres para que sean imputables y, en consecuencia, meritorios? ${ }^{71}$.

\section{APORIA DE PENSAMIENTO NECESARIO.}

El hombre desea y ama necesaria y naturalmente la felicidad objetiva, siempre que piense de hecho en ella. ¿Cómo no importa al entendimiento que piense de hecho siempre en ella? Ya en parte esta dificultad está resuelta. Las razones explicativas de esta falla, al menos aparente, en el psiquismo humano son múltiples. Nuestro autor las va señalando en diversos lugares de su obra.

a) Es la misma voluntad quien impone al entendimiento que piense en otra cosa, sin percatarse que así deja de pensar en su felicidad ${ }^{72}$.

b) La influencia de la imaginación en toda nuestra vida mental. Tengamos en cuenta que Tomás de Argentina, como escolástico tomista, defiende que el objeto propio del entendimiento son las esencias de las cosas sensibles y materiales ${ }^{\mathbf{7 3}}$.

71 Es manifiesto que la libertad es una de las raices necesarias para el mérito en sentido estricto. No será la única fuente, pero sí es absolutamente indispensable, como puede verse en cualquier moral o ética. Psicológicamente vemos que tiene que ser así (II, d. 26-27, q. 1, a. 4).

72 "Voluntas, dum actu vult ultimum finem, ex sua libertate potest intellectui imperare considerationem alterius rei, non advertens quod intellectus simul plura ut plura intelligere non potest. Intellectus vero talem rem cognoscendo iuxta imperium voluntatis, immediate desinit a cognitione finis: quo facto voluntas avertitur ab eius volitione: cum per se non feratur nisi in cognitum: et de primo ad ultimum seipsam avertit, saltem per accidens, a summi boni actuali volitione" (I, d. 1, q. 2, concl. 2).

73. "Ens phantasiabile tam mediate, quam immediate, est adaequatum obiectum nostri intellectus pro statu praesentis vitae" (IV, d. 50, q. 1, a. 2).

"Omne illud, cuius notitia est deducibilis ex phantasmate, clauditur infra ambitum obiecti adaequati potentiae intellectivae pro statu praesentis vitae" (IV, d. 50, a. 1, a. 3).

"Eius obiectum adaequatum est ens phantasiabile mediate vel immediate... Ens phantasiabile immediate, quod proprie cadit sub phantasmate. Sed mediate, cuius cognitio argutive vel illative vel quocumque alio modo deducibilis est ex phantasmate, sive ex notitia eius, quod proprie cadit sub phantasmate" (I, Prol., q. 3, a. 4). 
c) También los sentidos externos y la misma estructura somática del hombre condicionan parcialmente la atención mental, haciendo que no se aplique de hecho al objeto beatífico o felicidad objetiva ${ }^{74}$.

d) El dato psíquico de que el conocimiento sobre la felicidad, en el estado presente de cosas, es imperfectísimo, explica, en cierto modo, que la felicidad a veces, no ejerza una atracción irresistible y arrebatadora ${ }^{75}$.

De esta forma, pretende el autor dar una explicación psicológica del hecho de que no siempre el entendimiento considere la felicidad objetiva, no obstante que su conocimiento actual suscita en el hombre un amor y un deseo naturales y necesarios.

\section{¿PUede Ser InÚtil Un Deseo natural y neCesario?}

Nos situamos en una perspectiva teológica, aunque la solución venga dada desde una perspectiva filosófica. ¿Qué pasa con los condenados? ¿Qué destino espera a los niños muertos en solo pecado original? ¿Qué razón suficiente de ser se puede asignar a su deseo natural y necesario a la felicidad? Este deseo natural y necesario ¿tendrá como término un imposible, un "irracional", el absurdo? ¿O se volatiliza en ellos tal deseo natural y necesario? ¿Se tratará de un deseo natural y necesario absolutamente sin sentido alguno?

El dramatismo del problema con sus tremendas consecuencias estremece el fondo del alma. ¿Qué se puede responder? ¿Es posible alguna respuesta? ¿Es viable alguna solución satisfactoria? ¿Estaremos condenados a tener que bracear en pleno misterio? Sí, misterio de la libertad humana y del amor de Dios. Quizá sea la única palabra sabia, con sentido, que pueda pronunciar el hombre: ¡escalofriante misterio!

Desde luego parece que el deseo natural y necesario a la felicidad no apunta a cosas imposibles. La felicidad objetiva, eso creemos, nos es accesible. Todo depende, en parte cuando menos, de que la voluntad se ponga en órbita, entre en el círculo de la luz y utilice los medios necesarios, dentro de un legítimo anhelo de ser feliz. ¿De modo libre? ¿De modo necesario? En cierto modo, ambas cosas a la vez. Somos un poco los artífices de nuestro destino eterno, responsables de nuestra eterna felicidad o de nuestra eterna desdicha. El deseo tiraba de nosotros hacia arriba. La meta estaba en la cima y había que subir. Nosotros, empero, optamos por sentarnos a media-cumbre. $Y$ no logramos el trofeo, la flor natural.

74 "Vehementia delectationis acceptae... periculosa tamen est: eo quod sua inebriatione iudicium impediat, quoad debitam considerationem eius" (II, d. 6, q. 1, a. 1).

75 "Loquendo de corpore obscuro et corruptibili, quia tale corpus est impeditivum intellectualis cognitionis" (IV, d. 49, q. 4, fol. 211v. col. 1). 
¿Será por eso vano el deseo hacia arriba, hacia la cima, enquistado en el mismo corazón del hombre?

¿Qué piensa Tomás de Estrasburgo? Como era de suponer, da soluciones completamente distintas, según se trate de adultos muertos en pecado mortal o de niños muertos sin bautismo.

1. Adultos: Dios los crea ordenados a la felicidad objetiva. Pero los hace libres. Por tanto, responsables de su destino. La causa, pues, de que se frustre el fin del hombre muerto en pecado es la propia libertad humana.

Por otra parte, el fin de la criatura, ni aún en los condenados, es plenamente frustrado, pues en ellos, por su culpa, brilla la justicia divina ${ }^{76}$.

2. Niños: Este problema, aunque también hiere nuestra sensibilidad, no es, sin embargo, tan dramático. El autor desgrana su pensamiento en tres conclusiones:

a) Los niños muertos sin bautismo no padecen pena de sentido. Sólo sufren pena de daño, careciendo de la visión de la esencia divina y de la fruición completa de la felicidad objetiva ${ }^{77}$. No logran el fin sobrenatural, pero logran el fin natural.

b) Los niños muertos en pecado original estarán privados para siempre de la visión beatífica de Dios. La razón fundamental consiste en la gratuidad absoluta de la visión inmediata de la esencia divina. El hombre, en cuanto hombre, es totalmente incapaz e impotente, por sus solas fuerzas naturales, de obtener la vida eterna ${ }^{78}$. Pero, aunque no logran el fin sobrenatural, sí consiguen un fin

76 "Cum solum illud dicatur fieri frustra, quod non fit propter aliquem finem" (IV, d. 50, q. 1, a. 1). Preguntamos: ¿no fueron creados para algún fin los mismos que culpablemente se han condenado? Indudablemente fueron creados para que dieran gloria a Dios y así se salvasen. ¿No es un fin digno y noble la propia felicidad? ¿Por qué no la han logrado? Porque no quisieron de veras. Eso es todo.

"Licet Deus nihil faciat frustra, quia quantum in se est omnia dirigit in suos fines; homo tamen, quia est liberi arbitrii, mala sua voluntate seipsum suo fine frustrare potest". Voluntad que hace uso indebido de su libertad, ahí está el nervio de su desviación moral y de su lógica sanción.

"Potest etiam dici, quod quantum ad divinum ordinem etiam illi, qui sunt in inferno, non sunt frustra: quia in ipsis relucet divina iustitia" (II, d. 33, q. 1, a. 3). Evitemos el equívoco al interpretar este último texto del autor. Dios no crea a nadie para manifestar en él su divina justicia. No rima esta versión con su doctrina. No es Dios quien condena. Son los mismos hombres quienes se condenan a sí mismos. Es más: enérgicamente repudia esa sentencia, cree, defendida por Tomás de Aquino y por Egidio Romano, cuando estudia el problema de la predestinación y de la reprobación ( $I$, d. 41 , q. 1, a. 2). "Quantum ad adultos causa reprobationis dici potest malus usus liberi arbitrii usque ad finem vitae in ipsis duraturus" ( $I$, d. 41 , q. 1, a. 1).

77 "Prima est, quod decedentibus in solo peccato originali non debetur aliqua poena sensus". ¿Por qué? "Illi peccato non debetur poena sensus, in quo nulla est conversio ad aliquod bonum commutabile". "Qui secundum nullum sensum peccavit, secundum nullum sensum a iusto iudice punietur in aeternum" (II, d. 33 , q. 7, a. 3).

78 "Decedentes in solo peccato originali puniuntur perpetua privatione visionis divinae essentiae". "Talis visio, cum sit omnino supernaturalis, non potest ab aliquo adipisci nisi mediante gratia Dei" (Ibid.). 
meramente natural. En cuanto es posible, ellos también serán plenamente felices.

c) Por la carencia de la visión inmediata de la esencia divina los niños muertos sin bautismo no padecen sufrimiento de ninguna clase. No sufren pena alguna ${ }^{79}$.

Los niños, pues, serán eternamente felices, mas con una felicidad puramente natural. Su inteligencia captará la verdad del orden natural y en su contemplación serán realmente felices. Conocerán las substancias separadas, conocerán a Dios en cuanto creador de todo y conocerán todas las verdades pertinentes al orden natural. Conocerán, en una palabra, toda la verdad naturalmente cognoscible, ya por especies creadas, ya por especies derivadas de las mismas cosas, incluso podrán tener ciertos conocimientos logrados "a posteriori" 80 .

\section{HERMENÉUTICA Y CRITICA.}

¿Por qué el hombre desea y ama natural y necesariamente su felicidad objetiva? ¿Por qué este deseo natural y necesario, implantado en el ser humano? ¿Qué sentido tiene semejante tendencia natural y necesaria hacia la bienaventuranza plena? ¿Qué implicaciones metafísicas se hallan entrañadas en este deseo natural y necesario? ${ }^{81}$.

Ciertamente es aquí, en un plano metafísico, donde se ha de situar el sangrante dramatismo y problematismo de esta cuestión tan existencial y vital a toda persona humana. Quizá sea la única manera justa y honda de plantearla, enfocarla

79 "Decedens in solo peccato originali ex praedicta carentia divinae visionis nullum sustinent cruciatum". Anotamos algunas de sus razones. "Nullus prudens cruciatur ex eo, quod sibi non datur illud, ad quod nullam habet nec habere potest habilitatem...". "Licet sint separati a Deo quantum ad contemplationem gloriae, quae est finis supernaturalis, non tamen quantum ad divinorum contemplationem naturalem...". "Istae animae sic decedentes, non appetunt beatitudinem gloriae secundum propriam rationem: quia, ut sic, non cognoscunt eam, cum nec habeant lumen gloriae, nec lumen fidei, in quibus luminibus tantummodo talis beatitudo cognosci potest secundum propriam rationem" (II, d. 33, q. 1, a. 3).

80 "Etiam illi, qui decedunt in originali peccato solo, non sunt frustra, quia quamvis non consequantur finem supernaturalem, consequuntur tamen finem naturalem. Possunt enim habere evidentiorem contemplationem, quam quicumque philosophus umquam habere potuit in hac vita, quae quidem contemplatio est naturalis finis hominis virtuosi" (Ibid.). En el cuarto libro establece algunas proposiciones respecto al conocimiento de las almas separadas. Desde luego, conocen algo. ¿Qué? Los ángeles o almas separadas. Conocen también todo io naturalmente inteligible. Respecto de Dios afirma: Quaelibet anima separata potest naturali cognitione videre Deum esse creatorem, et causam cuiuslibet intelligentiae, praeter hoc, quod divinam essentiam videat beatifice" (IV, d. 50, q. 1, a. 1). En este mismo lugar nos habla de los modos distintos cómo conoce todos esos objetos.

81 Ya sé que aparentemente Tomás no plantea así el problema ni lo resuelve. Inmediatamente ubica este deseo natural y necesario en la voluntad, de acuerdo con su tesis y de otros de que el alma no es principio inmediato de operación. El alma alcanzaría la felicidad por la voluntad. Pero ¿no dice que el alma es principio natural de potencias? ¿ $\mathrm{Y}$ principio necesario? 
y entenderla, para trascenderla, dando una solución adecuada. Es el medio más apto para que logre la dimensión ontológica a que tiene derecho, para inferit luego las consecuencias implicadas en ambas premisas: deseo natural y necesario hacia la felicidad. Deseo natural y necesario instalado en todas las cosas en cuanto aman su bien y su perfección. Por tanto, también deseo natural y necesario en el hombre, responsable de su eterno destino. De modo consciente y de modo menos consciente, el hombre siempre tiende hacia su felicidad objetiva. $Y$ respecto de ambos modos de tender el hombre hacia su felicidad, el deseo es natural y necesario. ¿Por qué? La respuesta desde una filosofía que distingue realmente las facultades del alma o que no distingue realmente las facultades del alma viene a ser idéntica hasta cierto punto. En el peor de los casos, caso de distinción real de potencias y alma, no debemos olvidar que las facultades no son concebidas como meros accidentes. Son concebidas como propiedades metafísicas del alma. Que en otras palabras se suele llamar "esencia consecutiva", no "esencia constitutiva". Son cualidades metafísicas que necesariamente fluyen del alma. Son algo que pertenece, en cierto modo, al alma. Sus deseos necesarios, pues, serán ciertamente naturales desde un punto de mira profundo.

¿No implica ello que el deseo natural y necesario configura la misma esencia humana? ¿No modela este deseo la interioridad del ser humano? ¿No se refiere a la estructura íntima de la persona humana su tendencia natural y necesaria hacia la felicidad? ¿Cómo se explica que sea natural —radicado en la naturaleza- y necesaria -inevitablemente radicada en la naturaleza humana-? ¿No será natutal y necesaria porque se conforma o porque viene exigida por la consistencia metafísica de la persona humana, consciente y libre por persona?

Todo esto es importante con un gran mensaje dentro. Cada ser se convierte en símbolo de trascendencia, en marcha no hacia sí, sino hacia la "Alteridad". Está en marcha hacia el "Otro". El "tú" y el "yo" entendidos en función del "Otro". ¿No es ésta una exigencia metafísica palpitante en "cette pauvre apparence d'etre", que diría Blondel? ${ }^{82}$. Ello es signo y expresión de la radical penuria, de la propia mendicidad y de la insultante miseria del ser contingente. Equivale a una confesión pública y privada de la propia contingencia, ya que al no encon-

82 H. DE LUBAC, Blondel et Teilhard de Chardin: Correspondance commentée par Henri de Lubac, París 1965, 35. En el artículo ya citado tiene Rostenne acuñada una expresión feliz: "Notre pauvreté ontologique": "Pour une Metaphysique de l'Amour" (Giornale di Metafisica 21 (1966) 246).

Este problema de la contingencia, de la relación metafísica de las cosas a Dios lo hemos rozado ya más arriba. El autor lo afronta al estudiar el tema de la creación (I, d. 30, q. 1, a. 1, 2, 3 y 4). "Oportet igitur quod relatio creaturae ad ipsum Deum sit aliquid reale existens in ipsa creatura, quo ad Deum creatura refertur". "Relatio creaturae ad Deum est naturalis, cum ipsa naturaliter dependeat a Deo secundum totum suum esse". "Quamvis creatura totum suum esse sive ad se sive ad aliud totaliter habeat a Deo". "Creatura realiter dependet a Deo et ad ipsum ordinatur". Son, sin duda, frases de un profundo contenido metafísico. 
trar en sí su felicidad - su razón de ser- tiende natural y necesariamente hacia su felicidad - razón última de su ser-.

Las raíces supremas de este deseo, su principio vital, se ahondan en la intimidad del ser humano. Aún en el mismo condenado existe este deseo natural y necesario. $Y$ sabe, al mismo tiempo, que ya es imposible satisfacerlo. Se siente naturalmente atraído hacia su felicidad objetiva, mas siente en su rostro la bofetada de la misma que le rechaza. No es viable ya la paz. No hay posibilidad de diálogo. No hay lugar al abrazo naturalmente exigido entre la felicidad formal y la felicidad objetiva. Por una parte, tiende necesariamente hacia Dios. Por otra, tiene la evidencia de su imposibilidad. E irrumpe, brutal, en el hombre la dilacerante tensión humana. Se considera rama desgajada, hueso descoyuntado. He aquí, acaso, la pena de daño. Se da cuenta de que su deseo natural y necesario jamás podrá ser eficaz ni podrá, por tanto, lograr su objeto. Todavía más: ¿ inin esta tendencia natural y necesaria a Dios podría darse la pena de daño? El simple hecho de no ver a Dios, ¿sería suficiente para la pena de daño? Si no se diera esta tendencia natural y necesaria hacia Dios, ¿a qué se reduciría la pena de daño?

En el fondo, pues, tenemos esto: La ley metafísica que regula la dinámica vital es su enfermedad, su contingencia, su imperfección de ser. No se tiene aún la perfección. No se tiene la felicidad. No se está en posesión pacífica de la verdad, bondad y belleza del ser. Cada ente es un retazo, un muñón de estas perfecciones. Las cosas, que son así, no pueden estar contentas consigo mismas. Hay en ellas $y$ en el hombre una llama encendida que anhela las alturas, que va hacia arriba. No se sacian nunca, especialmente el hombre, que es una capacidad casi infinita de conocer y de amar, con una mente siempre en curiosa fermentación ideológica y con un corazón siempre en oleaje constante de afectos. He aquí la dialéctica de la inteligencia y he aquí la dialéctica también de la voluntad. En última instancia: he aquí la dialéctica del ser finito y la dialéctica del hombre. Todos los seres aman el bien y corren tras él. Es un derecho ontológico. Es un "elan vital", nacido en el alma del ser, que en toda coyuntura se dirige hacia su perfección, hacia su felicidad. Es su ley interna, identificada con su misma esencia.

Pero, ¿todos los seres siguen de idéntica y análoga manera su singladura hacia la felicidad? Desde un plano metafísico, acaso sí. Mas desde un plano psicológico, en absoluto. En los animales, por ejemplo, los impulsos se disparan automáticamente, de acuerdo con su ser. El hombre es racional, es persona, es libre. Sus impulsos, en parte al menos, estarán sometidos al resorte de la voluntad. Sí, los deseos humanos, hechos conscientes, tienen como causa inmediata el conocimiento o siquiera como condición absolutamente necesaria. Se conoce el objeto beatífico y emerge, casi espontáneamente, la tendencia y el deseo psicológicos. El hombre también huye del dolor. No ama el sufrimiento. Ama su bien, su felicidad, aquello que lo hace feliz. A veces parece que ama el dolor, pero en lo que tiene de purifi- 
cador, de positivo, de catártico e incluso de higiénico. Mas esto ya es un bien y un bien muy positivo.

A todo lo largo de este artículo se ha repetido una y otra vez que el hombre que conoce actualmente su felicidad objetiva, ese hombre la desea y la ama de modo natural y necesario. Es 'más: constituye la ley que ahorma el desarrollo de la vida humana. Sin embargo, ¿no se puede contravenir esta ley, que preside la génesis y la maduración de la actividad rica y compleja, consciente e inconsciente del hombre? ¿Qué nos constata la experiencia vital de cada momento? Así debiera ser, para que la vida fuese lógica y coherente, llena de sentido y de "logos" interno. Pero ¿no resulta a menudo ilógica, montada sobre el absurdo o quimera? ¿No se vuelve a cometer la misma acción desordenada, aún a despecho de la náusea dejada en el alma? ¿Qué dice el borracho en sus ratos de lucidez? ¿Cuál es la verdad del hombre dormido en brazos de sus sentidos? En sus intervalos de lucidez, el borracho se avergüenza y el impúdico se vela el rostro. Uno y otro saben, con todo, lo que hacen. Su conciencia se encarga de recordárselo. La realidad, pese a ello, es deprimente: un cortejo fúnebre, diría Pío XII, de almas muertas y moribundas se pasea por las calles, hundiéndose más y más en el abismo, sordas e inatentas a los gritos impotentes de la conciencia. ¿O es que acaso creen que el vino y las mujeres les van a hacer eternamente felices? ¿Qué es lo que entonces pretenden? ¿Qué factores subterráneos y ocultos condicionan su conducta? Y lo más grave es que algunos piensan en su felicidad, en Dios; pero le vuelven la espalda. Acaso, por esto: porque son libres o porque no son del todo libres. Es la pena de las cadenas irrompibles, casi, de las costumbres enraízadas en el corazón humano.

Aún sigue flotando la pregunta en el aire. ¿Cómo se desea y se ama la felicidad objetiva? ¿Se anhela siempre la felicidad?

Ahí está la vida. Ahí está la historia. Ahí está la experiencia personal y la experiencia de los demás. De todas partes nos llega el ramalazo. ¿Por qué se desvían del verdadero camino los hombres sabios, tantos teólogos como incurrieron en la herejía? ¿No sabían que Dios era su auténtica felicidad? ¿No era su convicción honda, casi vital? ¿Cómo se explica ese desdoblamiento personal? ¿Por qué el deseo natural y necesario hacia la felicidad no informa enteramente su actividad anímica: intelectiva y afectiva? El deseo y amor a la felicidad, cuando se piensa en' ella, ies realmente natural y necesario desde un punto de vista psicológico? ¿Qué clase de conocimiento se exige para que brote el deseo natural y necesario de felicidad?

Es posible que toda esta problemática quede en cierto modo iluminada con las siguientes proposiciones:

a) Mientras el hombre vive en este mundo sólo tiene un conocimiento im. 
perfecto de la felicidad, que, lógicamente, suscitará un deseo natural y, si se quiere, necesario pero imperfecto de la misma.

b) Nadie en este mundo goza del privilegio de lograr y poseer un conocimiento pleno, absoluto y total de su felicidad objetiva.

Acaso, teniendo en cuenta estas dos proposiciones, que en el fondo son una sola, no sea tan difícil resolver las múltiples objeciones, remontadas contra la doctrina del eximio teólogo y filósofo agustino: Tomás de Argentina o de Estrasburgo $(\uparrow 1357$, en Viena).

P. Pedro Vara, O. S. A. 